\title{
Gambling impacts on Aboriginal communities in New South Wales, Australia: community leaders' perspectives
}

Helen M Breen ${ }^{*}$, Nerilee Hing and Ashley Gordon

\author{
* Correspondence: \\ helen.breen@scu.edu.au \\ Centre for Gambling Education and \\ Research, School of Tourism and \\ Hospitality Management, Southern \\ Cross University, Military Road, \\ Lismore 2480, NSW, Australia
}

\begin{abstract}
Gambling affects communities in many ways, yet relatively little research has investigated community level impacts of gambling in the context of Indigenous communities. To help address this gap in research, this research investigates the impacts of gambling on Aboriginal communities across New South Wales, Australia. Thirteen Aboriginal community leaders were interviewed by an Aboriginal member of the research team. Interviews were semi-structured, in-depth and conducted by telephone. The results showed some culturally distinctive positive and negative gambling impacts were being experienced across different Aboriginal communities. Positive impacts were reported as collective socialising and the opportunity to win money. Negative impacts were said to be community deprivation and cultural obligations not being fulfilled. Several important public health strategies to reduce negative gambling impacts were suggested. These were to enable self-recognition of gambling difficulties by the gambler, to use already established Aboriginal support groups to assist in this process, and to design and provide culturally appropriate public education and gambling awareness programs targeted at a community level. Recognising differences between communities, involvement by local Aboriginal people in developing and providing public health programs is recommended.

Keywords: Gambling impacts, Aboriginal communities, Indigenous, Australia, Problem gambling
\end{abstract}

\section{Background}

"Some communities face widespread problems ... Some Indigenous communities fall into this group ..." (Productivity Commission, 2010, p. 3.8).

Gambling is an acceptable pastime for many people in society. Internationally, the liberalization of gambling opportunities since the mid-1990s has expanded the variety of gambling types available and increased gambling choices for most people (Reith, 2006). For example, in Australia about 70-75\% of adults gamble at least once per year in hotels, clubs, newsagents, casinos, off-course betting agencies and online (Productivity Commission, 2010). Gambling expenditure trends are stabilizing in most states and territories but in New South Wales (NSW) average gambling expenditure rose $4.4 \%$ in the past year to $\$ 1,318.67$ per adult in 2008-09 (Office of Economic and Statistical Research (OESR), (2011). A small proportion of adults in Australia (up to 2.1\%) experience moderate risks and problems in controlling their gambling (Productivity Commission, 2010). The harm

(c) 2013 Breen et al.; licensee Springer. This is an Open Access article distributed under the terms of the Creative Commons Attribution License (http://creativecommons.org/licenses/by/2.0), which permits unrestricted use, distribution, and reproduction in any medium, provided the original work is properly cited. 
arising from excessive or problematic gambling affects problem and at-risk gamblers, their families, friends, employers, communities and society in a widening circle. Their physical and mental health may suffer and their wider financial, legal, social, family and community domains are usually affected (Thomas \& Jackson, 2004; 2008). Thus, for the general population, gambling problems give rise to serious impacts, the burden of which spread outwards from the gambler.

However, as (McMillen 2009) points out, at the level of local communities, gambling behavior, policy impacts, community harm and wellbeing varies from one locality to another. Gambling can have different local impacts, depending on its regional prevalence and the nature of the areas themselves (Productivity Commission, 1999). Further, how gambling affects smaller cultural and/or disadvantaged groups in the population is not well known. Most gambling studies, (Raylu and Oei 2002) maintain, are Western-based with results often generalized to other cultural groups creating a research vacuum. Certain cultural groups appear to be more vulnerable to gambling uptake and to the development of problem gambling (Raylu \& Oei, 2004), a suggestion supported by Marshall and Wynne (2003) in research conducted with First Nations people in Canada. In fact, Williams, Rehm and Stevens (2011) called specifically for more research into impacts of gambling on Indigenous peoples, specifically Canadian First Nations, Australian Aborigines, and New Zealand Maori and Pacific people when assessing the social and economic impacts of gambling. Our paper attempts to reduce this knowledge gap for Aboriginal Australians. While not attempting to assess the socio-economic impact of gambling on Aboriginal communities, this paper investigates the positive and negative impacts of gambling on their communities, as perceived by Aboriginal community leaders.

Aboriginal Australian people comprise a small group in the national population (2.5\%) which is relatively young, with about $27 \%$ living in remote regions (compared to $2 \%$ of non-Aboriginal Australians) and about 30\% living in major cities (Australian Bureau of Statistics [ABS], 2006, 2012). Many Aboriginal Australians are vulnerable in terms of disproportionate levels of community health, social, economic and environmental disadvantage (ABS, 2012; Australian Institute of Health and Welfare [AIHW], 2011; Bailie, Stevens \& McDonald, 2012). Experiencing higher rates of risk factors for smoking, alcohol and substance misuse (AIHW, 2011), knowledge about gambling and its impacts is very limited (Breen, 2012; Cultural \& Indigenous Research Centre Australia [CIRCA], 2011; McMillen \& Donnelly, 2008; Stevens \& Young, 2009). Any activity increasing financial problems among vulnerable groups can only have a negative effect on their overall well-being (Reith, 2006). In fact (Reith 2006) calls for research to examine the ways and the extent that gambling and problem gambling exacerbates disadvantage.

Gambling has emerged as a significant public health issue for many groups in society (Korn \& Shaffer, 1999). Investigating gambling from a public health perspective has broadened the field from just investigating individual gambling and gambling-related problems to investigating the health and wellbeing effects of gambling on individuals, families and community groups. A key reason for this broadening is to identify public health implications of gambling for different groups. Treating gambling within a public health framework also underpins the use of models of gambling harm minimization, the generation of social conditions which protect gambling consumers, for treatment 
and for early identification of those at risk of developing gambling problems (Korn, Gibbons \& Azmier, 2003). Research efforts to identify and potentially limit harmful gambling impacts are an essential component of good public health practice.

Also integral for public health investigations is the need for balanced research, recognizing and documenting positive and negative aspects of gambling. Critical of some gambling investigations, Korn (2000) suggests that when negative impacts are the focus of a gambling investigation, the contrasting positive impacts (if included) are often treated superficially. Korn and Shaffer (1999) argue for a balanced approach stating that an evaluation of social costs and possible benefits must be included when investigating impacts of gambling on communities. In Australia possible benefits of gambling for Aboriginal people have been reported as relaxation (Dickerson et al., 1996), socializing, enjoyment, winning (Breen et al., 2011; McMillen \& Togni, 2000) and acceptance (Breen, 2012). Key negative consequences have been identified as financial hardship (Dickerson et al., 1996; McDonald \& Wombo, 2006; Stevens \& Young, 2009) family and children relationship problems (Breen et al., 2011; CIRCA, 2011; McMillen \& Donnelly, 2008;) and community difficulties such as alcohol and other drug use while gambling, crowded housing and hygiene and nutrition impacts on children, their carers and the elderly (Stevens \& Bailie, 2012; Hunter, 1993; McKnight, 2002; Phillips, 2003). Most prior research has been conducted in limited geographical regions so it remains unknown if these results are common for Aboriginal people across the state of New South Wales.

Aboriginal Australians, the original people of Australia, are identified culturally as a community. The word community is used to describe Aboriginal groups by their kinship, language or belonging to a particular place or country (Altman \& Smith, 1992). Demonstrating belonging to a community, about two-thirds (62\%) of Aboriginal adults identify with a clan, tribal or language group (AIHW, 2011). Within Aboriginal law, rights are based in the community where family and community are more important than the individual (Randall, 2003; Wright, 1997). Upholding traditional values, fulfilling reciprocal obligations and maintaining kin relationships are important for the overall health and well-being of the community. Thus, any investigation of Aboriginal gambling should include community impacts.

Therefore the aim of this paper is to explore the impacts of gambling for Aboriginal communities throughout New South Wales, Australia. Using a public health paradigm, we report positive and negative impacts of gambling in Aboriginal communities and how they might be addressed, as identified by Aboriginal community leaders.

\section{Method}

Permission for this study was gained from the Aboriginal Health \& Medical Research Council of NSW (AHMRC) (Ethics no:760/10) and a university ethics committee (Ethics no: ECN-10-178).

A qualitative, interpretivist approach was used to consult with people knowledgeable about gambling in Aboriginal communities. This approach is based on the assumption that reality is constructed by people interacting with each other, and is focused on empathic understanding of people's social and cultural contexts (Gubrium \& Holstein, 2000). 


\section{Participants}

Thirteen Aboriginal community leaders (nine men and four women), from different regions across NSW comprising three urban, four regional, four rural and two remote locations, consented to be interviewed for this research. Nine participants were democratically elected with a two year mandate to represent their Aboriginal constituents. The other four participants were well-known people appointed to regional positions, representing community health services, welfare and sport. These leaders individually and collectively have a high degree of participation and involvement with their local communities to provide and manage Aboriginal community services. With solid community involvement, their personal experience of gambling, and their observations of and knowledge about gambling in the communities they represent, these 13 participants provided in-depth information about Aboriginal gambling in their home regions.

\section{Research questions}

Using telephone interviews, all participants were asked the same set of questions by an Aboriginal male researcher. Interviews were deliberately unstructured and guided by a few overarching questions to allow participants to articulate the nature and extent of gambling's impacts on their community, as they perceived them to be. The majority of interviews lasted longer than one hour. They were recorded and transcribed verbatim. Core research questions were as follows:

1. Can you describe any positive effects of gambling on local Aboriginal individuals and families?

2. Are there any positive effects of gambling for the community?

3. Can you describe any negative effects of gambling on local Aboriginal individuals and families?

4. Are there any negative effects of gambling for the community?

5. What could Aboriginal people do collectively to reduce negative gambling impacts in their communities?

\section{Data analysis}

Thematic analysis was used to analyse the interviews. As suggested by Braun and Clarke (2006) each interview was coded, analysed and interpreted in a process that was reviewed and repeated many times. Eventually important themes were drawn from the raw data. A theme captures something important about the data in relation to the research aim. To further ensure confidence in the results, Nvivo software V.8 was used in the coding and analysis and to review the emerging pattern of themes (QSR, 2008). Using this software also facilitated inter-rater reliability between researchers and joint refinement of themes. Emergent themes are discussed below.

\section{Results and discussion}

Key themes explored in the interviews centred on positive and negative gambling impacts and suggestions for reducing identified negative impacts in communities. 
Quotations highlighting personal experiences reveal examples of issues that impact on communities and the participants as well.

\section{Theme one: collective socialising and the opportunity to win money}

In relation to their perception of positive gambling experiences, two themes emerged from the majority (8) of the participants: collective socialising and the opportunity to win money. In contrast, five participants could not see anything positive about gambling.

Collective socialising was said to include socialising with a congenial group, cultural acceptance by companions, the opportunity to reminisce about historical events and having some temporary relief from pressures at home. Group socialising, cultural acceptance and story-telling appear to support some collective elements of Aboriginal society. As a minority group with historically disrupted relationships, many Aboriginal communities have been isolated from one another on cattle stations, religious missions or Aboriginal reserves, so that social activity which re-unites people is highly valued (Randall, 2003). Opportunities for people to gather or congregate are important (Martin, 2008). With an oral tradition of story-telling, remembering and passing on community history is a vital aspect of many Aboriginal societies, including Australian Aboriginal people (Phillips, 2003). Typical responses indicating collective socialising were:

"There are positives ... allows that social interaction and people aren't ostracised in a sense, they know where they fit in. They know there'll be a group of people doing something where they can participate. That's a positive".

"The only positive thing that I can see out of this is our mob coming together. You go to a pub or a club and it's the only thing and you can see these people and these people. It's communal".

"It's a get together ... have a good time and remember the glory days."

In terms of winning money, the participants reported that the opportunity to win money, to have a life-changing win and being able to purchase items for family needs were important for many community members. For communities experiencing social and economic disadvantage, the chance to win extra money to improve living conditions and aspire to a better life was attractive. Reflecting this theme of winning, some people said:

"Some of our people have won a lot of money. Our people come from a poor background and they see it [gambling] as a way to get that quick fix or to try to get ahead".

"If you win ... it helps them, sets them up for the rest of their life, just to win some nice money".

"They might be able to go and buy their kids something or for themselves or for the house".

A mixed response was provided by one person who recognised from prior experience the positive collective socialising features of gambling and negative consequences for him resulting in his abstinence from gambling. He said: 
"I know when I used to go in there of a Saturday afternoon and I'd sit around and be with all the brothers sitting there and we'd be laughing and giggling amongst ourselves and that social was the one thing that I really miss because ... well if I go to the pub I know that I might be tempted to gamble so I'll avoid going to the pub altogether, I'll avoid going to the club altogether. You shut yourself out from all of those things".

\section{Theme two: community deprivation and unfulfilled cultural obligations}

In relation to the perception of negative gambling experiences, two themes emerged from the majority (12) of the participants: community deprivation and unfulfilled cultural obligations due to excessive gambling.

Community deprivation was seen to arise in part from a long-held respect for traditional Aboriginal obligations to share resources with those in need. Based on extensive relationship networks, Aboriginal Australians are expected to be responsible for the care of others and expect reciprocal treatment in return (Randall, 2003). Thus, when gamblers exhaust their funds, they may ask for and expect assistance from others. The provision of extra funds for gambling may lead to a ripple effect of negative consequences within a community. The progression of interrelated losses and debts that affect the gambler may radiate outwards in a circle of harmful consequences affecting many other people, with increasing high economic leakage and social adversity as indicated by McKnight (2002). Consistent with Hunter (1993), the opportunity costs as a result of gambling losses also constrain community development by limiting resources available for other projects. When the burden of debts was shared collectively, the entire community was poorer as a result. A summary of these ideas can be seen in people's responses:

"If someone gambles all their food money our mob will all bail each other out and buy it for them and provide food for the family to have so they're not left hungry. So people don't tend to have to go without, they more or less look after each other".

"If it gets to the stage where it's affecting their family and their family has to depend on other agencies to assist them, well the burden it places on the agencies affect the community as a whole ... it connects everyone into a poor place".

Negative cultural consequences were explained as unfulfilled cultural obligations, including a lack of community role models. Ceremonial practices and spiritual values were diminished for communities through a lack of regard for upholding cultural obligations. Important obligations include maintaining harmony within and between different worlds, material and spiritual (Martin, 2008). By developing a dependence on gambling, some leaders, Elders and role models are reported to neglect their responsibility to hand down traditional knowledge, history and culture to younger community members. The eventual cost of such risky gambling behaviour was believed to be serious for them and show a lack of loyalty and respect to their culture and community. A couple of respondents raised this by observing:

"Culturally it's bad for them as well because ... when they're consumed by some addiction they can't really open their mind to the rest of things that are important. If they can't even be loyal to their kids ... or family to make sure they're meeting their obligations, how can they meet their obligations in the community"? 
". . they're sort of gambling way outside their means and it's affecting them physically, mentally and spiritually, the repercussions could be suicidal tendencies".

A lack of leadership by role models affected children, families and communities in negative ways. For children a lack of leadership by people who ought to be role models, their parents and grandparents, was perceived to exacerbate the negative effects of gambling losses. The long-term prospects for some children were seen as being impaired by gambling problems in families, an outcome also reported by Stevens and Bailie (2012). For families, deteriorating relationships, a lack of ability to care for others and poverty led to extra responsibilities being placed on community assistance. Poverty affected people quickly, children were adversely affected in many ways and the need for awareness about gambling impacts was obvious to several participants, as these comments reveal:

"Leadership I suppose is one really big thing. Because the kids see what the parents do let alone the grandparents that they're staying with and finding that we're always broke and we have to wait until next fortnight. Then they get annoyed with their parents or the people that are spending the money in their families and so the relationships start to crumble".

"... that gambling is infringing on their ability to care for their family ... that's when it starts becoming a big issue and it not only affects them, it affects their immediate family and in the end the wider community".

"Obviously we're all related in some way and we all know each other and if that person is going down then it takes the family with them. They need more support services out there. I think more people are becoming aware now that gambling is an issue in the community".

Thus, collective socialising and the opportunity to win money were recognised by these leaders as positive for Aboriginal communities in NSW. In contrast, negative gambling impacts were reported as community deprivation due to damaging ripple effects extending through communities and cultural obligations not being fulfilled.

These results can be considered in relation to previous research that has identified a range of potential social and economic impacts of gambling at the community level. In reviewing 492 studies, Williams, Rehm and Stevens (2011) concluded that the most consistent economic impacts across all forms of gambling tend to be: increased government revenue, increased public services, increased regulatory costs, and either positive or negative impacts on non-gambling businesses. The most consistent social impacts across all forms of gambling were found to be: increased problem gambling, increased crime, increased socio-economic inequality, and more negative attitudes toward gambling. Apart from collective socialising, the current study found no evidence that the Aboriginal leaders perceived that their communities received any economic benefit from gambling, apart from the occasional gambling win. However, they did acknowledge substantial negative community impacts caused by gambling-related problems and the potential of gambling to widen socioeconomic inequalities. While gambling contributed to social cohesion, the impacts of more problematic gambling were perceived as being highly detrimental and threatened community and cultural cohesion. 
Theme three: what can aboriginal communities do collectively to reduce negative impacts of gambling?

Strategies to reduce negative gambling impacts for Aboriginal communities in NSW centred on recognition of gambling impacts, the creation of local support groups for gamblers and other community members, and the provision of appropriate public education and gambling awareness programs. All 13 participants contributed to these suggestions.

Having the gambler recognise the negative impacts caused by his or her gambling was considered a priority. Several participants saw the need to try to change people's thinking about their own gambling, to educate them that gambling was not a good way to make money or increase their income. However they realised that this was a difficult task on its own. Efforts needed to be supported by public education and the promotion of gambling awareness in a multi-faceted community approach, one conducted in a variety of places. One suggestion was for communities to take collective leadership for a program to be built around increasing public recognition of gambling impacts, consistent with findings by Stevens and Bailie (2012). Other suggestions were to encourage support for gamblers experiencing a lack of control and to reduce any shame associated with an admission of problems:

"I think we as an Aboriginal community need to get it out there in the community and say 'this is an issue within communities.' There are communities that are dealing with it but there are a lot of communities that aren't... I think it needs to be out there in people's faces ... we need to encourage those people that have an issue with it to seek the appropriate support... It's not a taboo subject, it needs to be out there with the rest of them ... spoken about freely ... to take that stigma away from it".

"I think the more that we get together and do these types of things ... local leadership ... is the go".

Empathic support groups were believed to be essential for sharing and maintaining links with other people who understand the nature and effects of gambling problems. These people may have experienced gambling problems and found unique self-help methods of recovery or control. Several participants felt that their communities had plenty of people with gambling experience to assist in setting up support groups to assist those gamblers seeking advice and help. This was considered a local and culturally appropriate step for gaining control over gambling and supported similar strategies proposed by Christie and Greatorex (2009). Participants were aware that mainstream gambling help was available but felt that local support groups would provide a more personal atmosphere and practical advice tailored to community-based conditions. These support groups were predicted to appeal to local Aboriginal people:

"I'm sure an Aboriginal person would be more comfortable in talking to another Aboriginal person in relation to this issue. The way Aboriginal people talk about issues puts Aboriginal people at ease than when you're talking to a white person. They talk to you like you are just another number. And the whitefella, they don't understand how to make us comfortable, the majority of them anyway, not all of them". 
"... obviously telling stories like the people who have been through it, who have lost and you can lose more than just your money. You can lose your family and sometimes suicide so it's talking about those bad situations".

"... the ability to be able to show people how to deal with it. Certainly if it's a group effort or in a personal atmosphere, how they wish to take that first step to address the issue".

Community education and awareness raising activities and resources should be made available at special events, festivals, in job agencies, medical organisations and community centres. By integrating education and awareness programs within community institutions, the overall effect should be a program adapted to specific community conditions and hopefully provided by trained, local people. In addition, other community education programs such as financial management sessions could be added to assist people in understanding their budgets. Budgeting and financial management workshops were proposed to assist people in seeing where their money was spent and in learning how to allocate money to meet future commitments. Participants recommended that financial education start in schools and be available for children. Some suggestions were:

"Communities could have a program, activities ... for people to participate in so there'll be the social interaction. Not be down on someone. Treat them as though it's a condition, a health condition that it's hard for people to control and say no to. And be more supportive".

"Financial workshops ... budget type workshops. Showing them how to make sure they prioritise with their money ... they can say 'well this is what I've got to pay and this is what I've got left over.' So they can see where if they do these proper things and have money left over then they've got more time and can do things with their family. It could help with the social outcomes and the recreational outcomes".

The next observation reflects many participant responses about the overall benefits of trying to reduce negative impacts of gambling and assist people in setting limits for their gambling so that it remains a social pastime.

"... to what point do you stop promoting because promotions can be an expensive exercise ... At the end of the day ... it creates more harmony in families and individuals that tends to rub off on the community ... so the community benefits overall and our kids are going to school, bills have been paid, everyone has a better outlook. That's a perfect world. I don't know if we'll ever get to that ... I think people enjoy the social aspects, let's not try and do it so it becomes a killjoy but give them something they can manage and to a point where people are happy ... happy with the situation and they're in control of the stuff".

Thus, three important strategies identified by participants to reduce harmful impacts of gambling are the identification of gambling impacts by gamblers themselves, the creation of local gambling support groups, and the provision of appropriate public education and gambling awareness programs. 


\section{Conclusion}

Much qualitative and quantitative work remains to be done exploring cultural influences and gambling especially by small groups in the population where vulnerability may be perpetuated through differences in history, socio-economic position and ethnicity. Although there were only 13 participants in this research and the results cannot be generalised, the findings represent the views on and experiences of gambling impacts as told by Aboriginal leaders across NSW. Future research might include larger samples of Aboriginal leaders, samples from other states and territories, and other stakeholders such as those from health and welfare services, community agencies and non-profit organisations.

Prior studies have indicated some variety in the nature of gambling consequences for Aboriginal people in Australia. However no previous in-depth investigation across the state of NSW with Aboriginal community leaders has revealed the nature and extent of gambling impacts on their communities as revealed here. Like many others, Aboriginal communities experience positive and negative impacts of gambling. However, our findings show that, being a culturally collective society and a disadvantaged one as well negative gambling impacts appear to lead to increasing community deprivation and to diminishing respect for meeting cultural obligations. The possibility of reducing community strength and the forfeiture of cultural knowledge linked to gambling losses, all new findings, threaten community well-being and have potentially damaging long-term cultural effects. Traditional Aboriginal priority for community and family values may be overturned if individual rights to gamble take precedence. These findings support ideas by Raylu and Oei (2004) that gambling by certain cultural groups has different meanings and impacts compared with Western-based populations. They also provide evidence for Reith's (2006) ideas about the intensity of harm and reduction in wellbeing by disadvantaged groups who gamble.

In contrast, the emergent theme supporting positive gambling impacts centred on collective socialising. This finding is potentially useful for protecting and enhancing public health interests within Aboriginal communities. Aspects of collective socialising, such as setting bet limits and time frames for gambling, could be integrated into culturally appropriate public health strategies designed to suit the individual requirements of Aboriginal communities. Implementing the basic principles of harm minimisation using collective socialising to meet most gamblers' needs, could make a vital contribution to ameliorating social costs associated with excessive gambling. Allowing for community variations and differences, it is important to seek the input of local Aboriginal people to ensure such strategies are appropriate for each community and thus able to be implemented effectively.

The research found that the participants' had considered public health options for their communities and provided responses that were practical and relevant. Participants saw the need to develop policies and interventions that promote community well-being by enabling and supporting gamblers as well as all other community members. Putting energy into gambling education and public awareness programs and assisting gamblers with problems through creating local support groups could raise levels of community well-being and reduce negative gambling impacts. These two strategies represent the public health principles of consumer protection and harm minimisation as articulated by Korn and Shaffer (1999) and Korn, Gibbons and Azmier (2003). This finding also 
demonstrates the positive thinking of these leaders who so obviously strive to enhance well-being within their communities. Ideally, bringing together leaders such as these and policy decisions-makers with access to resources for discussions on public health issues associated with gambling would be beneficial. One potential starting point for these discussions could be the public health principle that possible benefits should always outweigh social costs.

\section{Competing interests}

The authors declare that they have no competing interests.

\section{Authors' contribution}

All authors contributed equally to this research and subsequent paper produced here. All authors read and approved the final manuscript.

\section{Acknowledgement}

The authors acknowledge and thank the study participants for their generous input. This research was funded by an Australian Research Council Discovery Grant.

Received: 23 January 2013 Accepted: 27 March 2013

Published: 4 April 2013

\section{References}

Altman, J, \& Smith, S. (1992). Aboriginal Australia, aboriginal people of the northern territory. Canberra: Council for Aboriginal Reconciliation and ATSIC.

Australian Bureau of Statistics (ABS). (2006). National aboriginal and Torres strait islander health survey 2004-05, Cat. no. 4715.0. Canberra: ABS.

Australian Bureau of Statistics (ABS). (2012). Census of population and housing - counts of aboriginal and Torres strait islander Australians, 2011: Cat. no.2075.0. Canberra: ABS.

Australian Institute of Health and Welfare (AlHW). (2011). The health and welfare of Australia's aboriginal and Torres strait islander people, an overview: catalogue IHW 42. Canberra: AlHW.

Bailie, R, Stevens, M, \& McDonald, L. (2012). The impact of housing improvement and socio-environmental factors on common childhood illnesses: a cohort study in Indigenous Australian communities. Journal of Epidemiology and Community Health, 66, 821-831.

Braun, V, \& Clarke, V. (2006). Using thematic analysis in psychology. Qualitative Research in Psychology, 3, 77-101.

Breen, H. (2012). Risk and protective factors associated with gambling consequences for Indigenous Australians in north Queensland. International Journal of Mental Health and Addiction, 10(2), 258-272.

Breen, H, Hing, N, \& Gordon, A. (2011). Indigenous gambling motivations, behaviour and consequences in Northern New South Wales, Australia. International Journal of Mental Health and Addiction, 9(6), 723-739.

Christie, M, \& Greatorex, J. (2009). Workshop report, regulated gambling and problem gambling among aborigines from remote Northern territory communities: A Yolgnu Case Study. Darwin: Charles Darwin University.

Cultural \& Indigenous Research Centre Australia (CIRCA). (2011). Development of culturally appropriate problem gambling services for Indigenous communities. Sydney: CIRCA.

Dickerson, M, Allcock, C, Blaszczynski, A, Nicholls, B, Williams, J, \& Maddern, R. (1996). A preliminary exploration of the positive and negative impacts of gambling and wagering on Aboriginal people in NSW. Sydney: Australian Institute of Gambling Research.

Gubrium, J, \& Holstein, J. (2000). Analysing interpretive practice. In N Denzin \& Y Lincoln (Eds.), Handbook of qualitative research (2nd ed., pp. 487-508). Thousand Oaks CA: Sage Publications.

Hunter, E. (1993). Aboriginal health and history, power and prejudice in remote Australia. Cambridge: Cambridge University Press.

Korn, D. (2000). Expansion of gambling in Canada: implications for health and social policy. Canadian Medical Association Journal, 163(1), 61-64.

Korn, D, \& Shaffer, H. (1999). Gambling and the health of the public: Adopting a public health perspective. Journal of Gambling Studies, 15(4), 289-365.

Korn, D, Gibbins, R, \& Azmier, J. (2003). Framing public policy towards a public health paradigm for gambling. Journal of Gambling Studies, 19(2), 235-256.

Marshall, K, \& Wynne, H. (2003). Fighting the Odds. Perspectives on Labor and Income, 4(12), 5-13.

Martin, K. (2008). Please knock before you enter, Aboriginal regulation of Outsiders and the implications for researchers. Brisbane: Post Pressed.

McDonald, H, \& Wombo, B. (2006). Indigenous gambling scoping study - Draft report. Darwin: Charles Darwin University.

McKnight, D. (2002). From hunting to drinking: the devastating effects of alcohol on an Australian aboriginal community. Melbourne: Melbourne University Press.

McMillen, J. (2009). Book review I: is democratic gambling reform possible? Australian Review of Public Affairs. March. Retrieved on 15-4-13 from http://www.australianreview.net/digest/2009/03/mcmillen.html.

McMillen, J, \& Donnelly, K. (2008). Gambling in Australian indigenous communities: the state of play. Australian Journal of Social Issues, 43(3), 397-426.

McMillen, J, \& Togni, S. (2000). A study of gambling in the Northern Territory 1996-97. Sydney: Australian Institute of Gambling Research. 
Office of Economic and Statistical Research (OESR). (2011). Australian gambling statistics 1983-84 to 2008-09 (27th ed.). Brisbane: Queensland Treasury.

Phillips, G. (2003). Addictions and healing in Aboriginal country. Canberra: Aboriginal Studies Press.

Productivity Commission. (1999). Australia's gambling industries. Canberra: AusInfo.

Productivity Commission. (2010). Gambling. Canberra: Commonwealth of Australia.

QSR International. (2008), QSR V. 8. Melbourne: OSR International Pty. Ltd.

Randall, B. (2003). Songman, The story of an Aboriginal Elder. Sydney: ABC Books.

Raylu, N, \& Oei, T. (2002). Pathological gambling: a comprehensive review. Clinical Psychology Review, 22(7), 1009-1061.

Raylu, N, \& Oei, T. (2004). Role of culture in gambling and problem gambling. Clinical Psychological Review, 23(8), 1087-1114.

Reith, G. (2006). Research on the social impacts of gambling, final report. Edinburgh: Scottish Executive Social Research.

Stevens, M, \& Bailie, R. (2012). Gambling, housing conditions, community contexts and child health in remote indigenous communities in the Northern Territory, Australia. BMC Public Health, 12, 377.

Stevens, M, \& Young, M. (2009). Reported gambling problems in the Indigenous and total Australian population. Melbourne: Gambling Research Australia.

Thomas, S, \& Jackson, A. (2004). Influences on gambling behaviours and outcomes: A model for the design of effective interventions. Gambling Research, 16(2), 40-51.

Thomas, S, \& Jackson, A. (2008). Risk and protective factors, depression and comorbidities in problem gambling Melbourne: The Problem Gambling Research and Treatment Centre.

Williams, RJ, Rehm, J, \& Stevens, RMG. (2011). The social and economic impacts of gambling. Final Report prepared for the Canadian Consortium for Gambling Research. Lethbridge AB: Canadian Consortium for Gambling Research.

Wright, A. (1997). Grog war. Broome: Magabala Books Aboriginal Corporation.

doi:10.1186/2195-3007-3-10

Cite this article as: Breen et al.: Gambling impacts on Aboriginal communities in New South Wales, Australia: community leaders' perspectives. Asian Journal of Gambling Issues and Public Health 2013 3:10.

\section{Submit your manuscript to a SpringerOpen ${ }^{\circ}$ journal and benefit from:}

- Convenient online submission

Rigorous peer review

- Immediate publication on acceptance

- Open access: articles freely available online

- High visibility within the field

- Retaining the copyright to your article

Submit your next manuscript at $\boldsymbol{\sim}$ springeropen.com 